\title{
Modelling the egg components and laying patterns of broiler breeder hens
}

\author{
Nayara T. Ferreira ${ }^{\mathrm{A}}$, Nilva K. Sakomura ${ }^{\mathrm{A}, \mathrm{C}}$, Juliano César de Paula Dorigam ${ }^{\mathrm{A}}$, \\ Edney Pereira da Silva ${ }^{\mathrm{A}}$ and Robert M. Gous ${ }^{\mathrm{B}}$ \\ A Department of Animal Sciences, Faculdade de Ciências Agrárias e Veterinárias-UNESP, \\ Via de Acesso Paulo Donato Castelllane, 14884900, Jaboticabal, São Paulo, Brazil. \\ ${ }^{B}$ University of KwaZulu-Natal, Pietermaritzburg, 3209, South Africa. \\ ${ }^{\mathrm{C}}$ Corresponding author. Email: sakomura@fcav.unesp.br
}

\begin{abstract}
There is scant information about the reproductive process in broiler breeders, with which to develop a feeding strategy that will be economically optimal for these birds. This study aimed to model the egg production of a flock of broiler breeder hens, using non-isometric equations. The number of eggs produced by 60 broiler breeder hens aged 24-60 weeks was monitored, as was the weight of these eggs and the weights of the components, yolk, albumen and shell. Oviposition sequences and the number and length of pauses between sequences were analysed. Non-isometric functions were applied to predict the weight of the egg; yolk weight was predicted from the age of the hen, while albumen and shell weights were predicted from yolk weight; and egg weight was obtained by summing the component weights. The incidence of soft-shelled and double-yolk eggs was also determined. Yolk weight (YW, g) can be described as $\mathrm{YW}=18.03 \times\left(1-e^{-0.015 \times(t-103.4)}\right) \times e^{(0.001 \times t)}$, where $t$ is the age of the bird (days). The weights of albumen $(\mathrm{AW})$ and shell (SW) were based on YW predictions as follows: $\mathrm{AW}=14.38 \times \mathrm{YW}^{0.375}$ and $\mathrm{SW}=0.358 \times(\mathrm{YW}+\mathrm{AW})^{0.687}$. The rate of double-yolk egg (DY) production is described by DY $=2.28 \times e^{(0.209 \times \mathrm{TFE})}$, and the rate of soft-shelled egg $(\mathrm{SS})$ production by $\mathrm{SS}=1.126+0.148 /(1-0.024 \times \mathrm{TFE})-0.056 \times \mathrm{TFE}$, as a function of time from first egg $(\mathrm{TFE})$. On the basis of the results obtained, the model developed here is an accurate reflection of the changes that occur in the number of eggs produced by broiler breeders, as well as in the egg itself and in its components over the entire laying period. This model can thus be used in predicting the nutrient requirements of individual broiler breeder hens, which, when combined with simulated data from a large number of individuals, will accurately describe the laying performance of a flock of broiler breeders.
\end{abstract}

Additional keywords: abnormal egg, egg composition, egg production.

Received 3 August 2014, accepted 16 December 2014, published online 10 April 2015

\section{Introduction}

The worldwide increase in poultry meat consumption has increased the demand for hatching eggs from broiler breeder flocks and this has focussed attention on the importance of this component of the poultry industry. In spite of this increased demand for hatching eggs, very few studies with broiler breeder hens are reported in comparison to those with broilers and laying hens. Moreover, the most part of the information generated is owned by the major broiler breeding companies and may not be openly published. Nevertheless, both nutritionists of broiler breeding companies and researchers have been seeking to develop concepts for these birds. Establishing the most appropriate feeding program for broiler breeders and taking into account their particular physiological characteristics is a major topic of interest and study.

A sensible starting point in the process of designing an optimal feeding program for broiler breeders is to describe the potential egg output (rate of laying and egg weight) of these birds over the laying period. According to Gous and Nonis
(2010), five parameters may be used to describe the potential reproductive performance of broiler breeder hens, which are: age at sexual maturity; changes that occur in internal cycle length; changes in egg weight (yolk, albumen and shell) over time; body protein; and body lipid contents at sexual maturity. These parameters are required so that the nutrient requirements of a broiler breeder hen can be calculated. The rate of egg production of each hen over time is determined by the length of the ovulation sequences and the number and duration of pauses between the sequences that can vary according to strain, nutritional status and lighting program. This physiological process should be modelled together with an adequate nutritional program, to avoid the wastage of nutrients on the one hand and an undersupply of nutrients on the other; that is, the objective should be to provide an economically optimum amount of each nutrient to the flock each day. This implies that such a model should be stochastic in nature, taking account of the variation that occurs between individuals in all of the parameters mentioned above. Because of the relatively 
small amount of work published on broiler breeders, any research directed at any of the above aspects that describe the reproductive performance of broiler breeders would be welcomed by modellers working in this field.

According to Johnston and Gous (2007a), changes in the proportions of yolk, albumen and shell in relation to age of hen have been observed in laying hens and turkeys by previous researchers (Anderson et al. 1978; Harms and Hussein 1993; Hussein et al. 1993; Reidy et al. 1994; Rossi and Pompei 1995; Ahn et al. 1997; Johnston 2004). Only one paper (Nonis and Gous 2013) has addressed this issue in broiler breeders. Therefore, studying the changes that occur in these components in different broiler breeder strains would enable the observed increase in egg weight and the relative change in egg component weights with age of hen to be more accurately described, thus providing an important tool to understand this phenomenon.

The aim of the present study was, therefore, to collect more data on the changes that occur in internal cycle length, rate of egg production, egg component weights, and the proportion of abnormal eggs laid by broiler breeders from 23 to 60 weeks of age. This information could then be used to improve the accuracy of a model of the reproductive processes in broiler breeders, with a view to improving the way in which their daily nutrient allocation is calculated.

\section{Materials and methods}

\section{Bird housing and management}

The experiment was conducted at the Laboratory of Poultry Science, São Paulo State University, Faculty of Agriculture and Veterinary Sciences, UNESP, Jaboticabal, Brazil. Sixty broiler breeder hens of Cobb (parent strain) were used. The birds used in this trial, during the period of 1-18 weeks of age, were reared in floor pens on litter. The light management adopted was according to the strain guidelines. All birds received the same diet, and the amount was adjusted according to the average weight of birds each week, according to the lineage guide for each phase.

At the start of the trial, the birds were housed individually in laying cages at 18 weeks of age, to adapt to the facilities and to management. Each bird was considered an experimental unit. The experiment began at 23 weeks of age and ended at 60 weeks of age. The birds were fed a diet based on corn and soybean meal (159 g crude protein $/ \mathrm{kg}$ and $2850 \mathrm{kcal}$ metabolisable energy $/ \mathrm{kg}$ of feed), following the recommendations of the breeding company (Cobb 2012). Feed intake was adjusted weekly on the basis of the metabolic bodyweight of each bird. The lighting program used was $16 \mathrm{~h}$ of uninterrupted light and $8 \mathrm{~h}$ of darkness each day over the entire period.

The model to predict egg production was developed on the basis of observed data for persistence of egg laying, percentage of laying and the proportions of the egg components (yolk, albumen and shell). For this purpose, egg production and egg weight were measured daily.

\section{Analysis of sequence characteristics}

Data from daily egg production was used from each broiler breeder hen over a laying period of 10 months and was recorded in a Microsoft Excel $^{\circledR}$ spreadsheet (Microsoft Corporation, Redmond, WA, USA). Complete production records were used for the hens from April 2012 to January 2013, when the birds were 60 weeks of age. The complete data file was imported into an Egg Production and Sequence Analyzer program, version 3.00 (Zuidhof et al. 1999), which was used to analyse the performance of each hen in terms of the number of sequences and pauses, number of soft-shelled and double-yolked eggs, mean sequence length, mean pause length and the length of the prime sequence (or the longest sequence that follows several short egg sequences after the onset of lay). The number of ovulations was calculated from the number of single-yolked eggs plus twice the number of double-yolked eggs. The output files were imported back into Excel file, so as to interpret the results. Data were analysed using SAS statistical software, version 9.1 (SAS Institute 2002), using PROC NLIN to fit nonlinear models.

\section{Modelling internal cycle length (ICL)}

Eggs are laid in one or more sequences and separated by a pause period of one or more days, defined by consecutive daily ovipositions (Etches and Schoch 1984). The length of a sequence or pause is dependent on ICL (h) that is described by the lag (in hours) between successive ovulations.

The ICL for each hen on a weekly basis was calculated as follows: $\mathrm{ICL}=(\mathrm{DL} / \mathrm{LR}) \times 100$, where $\mathrm{DL}$ is the daylength $(24 \mathrm{~h}$ in this case) and LR is laying rate (\%). To simulate shorter egg sequences produced by many hens at onset of lay, Johnston and Gous (2006) suggested the use of the following line-plusexponential equation:

$$
\mathrm{ICL}=a+b \times\left(R^{\mathrm{TFE}}\right)+c \times \mathrm{TFE},
$$

where ICL is the internal cycle length (h), $a, b, c$ and $R$ are fitted coefficients $(a+b$ is equal to ICL when TFE $=0, R$ the rate of decrease and $c$ the rate of increase of the curve), while TFE is the time from first egg (days).

\section{Determination of the egg components}

The egg components (yolk, albumen and shell) were weighed on three consecutive days weekly at 26-45 weeks of age. After this period, sampling was made at 48, 51, 54, 57 and 60 weeks of age and 3100 eggs were measured in total. The method used to determine the weight of egg components was adopted from Hussein et al. (1993) and Harms and Hussein (1993). After weighing the eggs, they were broken and yolk was separated from albumen. Albumen was discarded and yolk rolled on damp paper towel. Any adhering chalazae were removed from the yolk in this manner. Eggs with ruptured yolk membranes were omitted from further analysis. Only intact yolks were weighed. The two shell halves were carefully washed to remove the albumen then they were left to dry at $21^{\circ} \mathrm{C}$ for $48 \mathrm{~h}$, before being weighed. The albumen weight was determined by subtracting the yolk and dry shell weights from the initial whole egg weight.

\section{Predicting egg weight}

Egg weight can be predicted as the sum of three components measured previously, namely, yolk, albumen and shell. The yolk 
weight (YW, g) was predicted from the age of the bird ( $t$, days) using a compartmental model (McMillan et al. 1970), described as

$$
\mathrm{YW}_{t}=a \times\left[1-\mathrm{e}^{-c \times(t-d)}\right] \times \mathrm{e}^{-x \times t},
$$

where $\mathrm{YW}_{t}$ is the yolk weight at Age $t$ (days), $a$ is the asymptotic value of the yolk weight at the maximum yolk weight, $c$ is the daily rate of increase in yolk weight, $d$ is the mean initial day of laying, and $x$ is the rate of decrease in yolk weight after the peak of yolk weight.

For the linear regression analysis, individual egg data were used to determine the allometric coefficients in the equations to predict albumen weight from yolk weight, and to predict shell weight from yolk + albumen weight. Albumen (AW, g) and shell (SW, g) weights were predicted using the allometric functions defined by Emmans and Fisher (1986), as follows:

$$
\begin{gathered}
\mathrm{AW}=a_{1} \times \mathrm{YW}^{\mathrm{b}_{1}}, \quad \text { and } \\
\mathrm{SW}=a_{2} \times \mathrm{ECW}^{\mathrm{b}_{2}},
\end{gathered}
$$

where ECW is the weight of the egg contents, i.e. yolk + albumen (g). After estimating each egg component weight, the mean egg weight $(\mathrm{EW}, \mathrm{g})$ can be estimated by the following equation:

$$
\mathrm{EW}=\mathrm{YW}+\mathrm{AW}+\mathrm{SW}
$$

\section{Models to predict abnormalities in egg production}

Double-yolked eggs occur when a second follicle in the hierarchy closely follows the first follicle at ovulation (or is produced simultaneously). The rate of double-yolked egg production is higher at the beginning of lay and rapidly decreases with age, as observed by previous researchers (Christmas and Harms 1982; Johnston and Gous 2007b; Gous and Nonis 2010). This process can be described by the following equation:

$$
\mathrm{DY}=\left(\mathrm{DY}_{\max }-\mathrm{DY}_{\min }\right) \times \mathrm{e}^{(-k \times \mathrm{TFE})}+\mathrm{DY}_{\min }
$$

where DY is the proportion of double-yolked eggs, DY $\mathrm{max}_{\max }$ is the DY value when TFE is zero, $\mathrm{DY}_{\min }$ is the minimal proportion of double-yolked eggs (DY) represented by an asymptotic value, TFE is the time from first egg (weeks) and $k$ represents the slope of the exponential function indicating the decrease in the proportion of double-yolked eggs with age. As DY $\min$ tends towards zero with the bird's age, Eqn 6 can be rewritten as follows:

$$
\mathrm{DY}=\mathrm{DY} \mathrm{max}_{\max } \times \mathrm{e}^{(-k \times \mathrm{TFE})} .
$$

The proportion of soft-shelled (SS) eggs produced was predicted using the following equation:

$$
\mathrm{SS}=a-b /(1-R \times \mathrm{TFE})+c \times \mathrm{TFE},
$$

where SS is the proportion of soft-shelled eggs, TFE is the time from first egg (weeks), and $a, b, c$ and $R$ are coefficients.

The coefficients for double-yolked and soft-shelled eggs were obtained by fitting Eqn 7 and Eqn 8 to data observed daily from 23 to 60 weeks of age.

\section{Evaluation of the models}

The models used to predict ICL, yolk and egg weights, doubleyolked eggs and soft-shelled were subjected to residual analysis as described by St-Pierre (2003). The residuals (er) were defined as er $=$ observed - predicted values. To assess the models obtained, the residuals (er) were plotted against the predicted values, according to the following model:

$$
e r=b_{0}+b_{1}\left(Y_{p}-\bar{Y}_{p}\right)+\varepsilon,
$$

where $e r$ is the residual value, $b_{0}$ and $b_{1}$ are estimated parameters of the linear regression, $Y_{p}$ is the predicted value (ICL, EW,YW, DY and SS), $\bar{Y}_{p}$ is the mean of all predicted values of ICL, EW,YW, DY and SS, and $\varepsilon$ is the error of the regression analysis. The slope of $e$ regressed on predicted values was used to confirm that the models are unbiased, that is, the slope $\left(b_{1}\right)$ close to zero. According to St-Pierre (2003), this slope can be calculated by $b_{1}=1-R^{2}$, that is, for a value of $R^{2}<1$, there is a positive slope that is greater as the $R^{2}$ value is lower. Therefore, a positive or negative slope of er on ICL, EW,YW, DY and SS is a test to assess the biased prediction.

\section{Results}

\section{Analysis of sequence characteristics}

Table 1 summarises important sequence characteristics. The number of pauses (50.28) closely followed the number of sequences (51.28), leading to the assumption that, for each bird, there will be one pause less than the number of sequences. The results showed that as the prime sequence length and sequence length increase, so the number of sequences and pauses become shorter. Moreover, the high standard deviations associated with the sequence characteristics were an indication that a few individuals with exceptionally short or long prime sequences may have a considerable influence on the mean values, although this is not clear.

The mean sequence lengths from 23 to 60 weeks of age are shown in Fig. 1. This figure clearly illustrates the laying cycles of broiler breeder hens with increasing age, starting their laying cycles with short sequences, followed by a rapid increase of the sequence length to the prime sequence at 28 weeks of age, and a subsequent decline thereafter. Mean sequence length reached a maximum between 26 and 31 weeks of age.

Table 1. Number and length of sequences and pauses, total eggs and age at first egg of Cobb broiler breeders, from 23 to 60 weeks of age s.d., standard deviation

\begin{tabular}{lrrrrr}
\hline Sequence characteristic & Mean & s.d. & Min & Max & Range \\
\hline Prime sequence length (days) & 22.38 & 13.50 & 4.00 & 68.00 & 64.00 \\
Number of sequences & 51.28 & 12.49 & 19.00 & 77.00 & 58.00 \\
Number of pauses & 50.28 & 12.49 & 18.00 & 76.00 & 58.00 \\
Sequence length (days) & 3.73 & 1.32 & 1.87 & 8.79 & 6.92 \\
Pause length (days) & 1.25 & 0.28 & 1.00 & 2.57 & 1.57 \\
Total eggs & 177.28 & 24.06 & 103.00 & 214.00 & 111.00 \\
Age first egg (week) & 24.68 & 0.99 & 22.40 & 27.90 & 5.50 \\
\hline
\end{tabular}




\section{Internal cycle length (ICL)}

On the basis of Eqn 1, the estimated values ( \pm s.e.) for parameters $a, b, c$, and $R$ were $25.4( \pm 0.435), 8.99( \pm 1.366)$, $0.072( \pm 0.003)$ and $0.748( \pm 0.109)$, respectively. The errors of the coefficients relative to the average values were $1.7 \%$ for $a, 15.2 \%$ for $b, 4.2 \%$ for $c$ and $14.5 \%$ for $R$. Therefore, the equation obtained was

$$
\begin{gathered}
\mathrm{ICL}=25.4+8.99 \times\left(0.748^{\mathrm{TFE}}\right)+0.072 \\
\times \mathrm{TFE}(P<0.0001) .
\end{gathered}
$$

The decrease in egg production with increasing age can be estimated using Eqn 10. For the first egg to be laid, the internal cycle length needs to be longer than $24 \mathrm{~h}$. This time will decrease with increasing age; in some birds it will be less than a daylength, and will increase again to $>24 \mathrm{~h}$. The curve fitted with the values predicted by Eqn 1 is shown in Fig. 2.

\section{Modelling egg component data to predict egg weight}

\section{Modelling yolk weight}

Yolk weight (YW) was estimated using the observed values in Eqn 2. The coefficients $a, c, d$ and $x$ estimated for YW were 18.03 $( \pm 0.955), \quad 0.015 \quad( \pm 0.002), \quad 103.4 \quad( \pm 4.698)$ and -0.001 $( \pm 0.0001)$, respectively. The errors of the coefficients relative

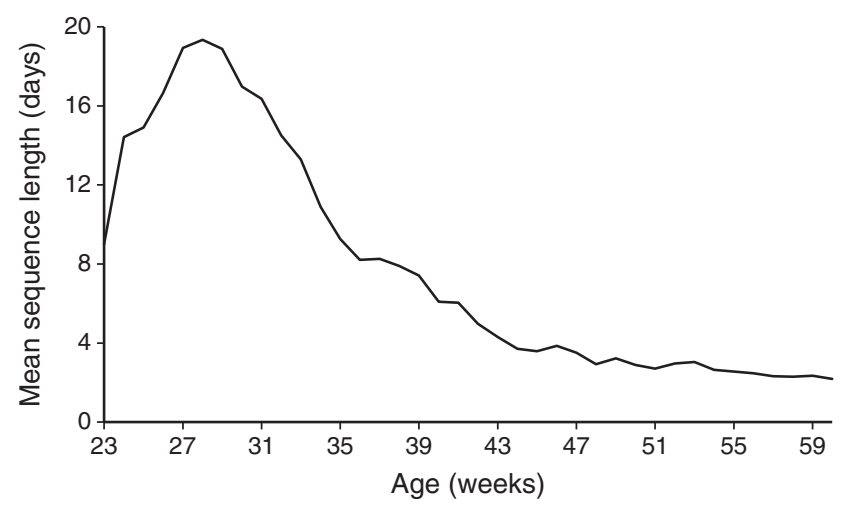

Fig. 1. Mean sequence lengths for broiler breeder hens of Cobb strain, from 23 to 60 weeks of age.

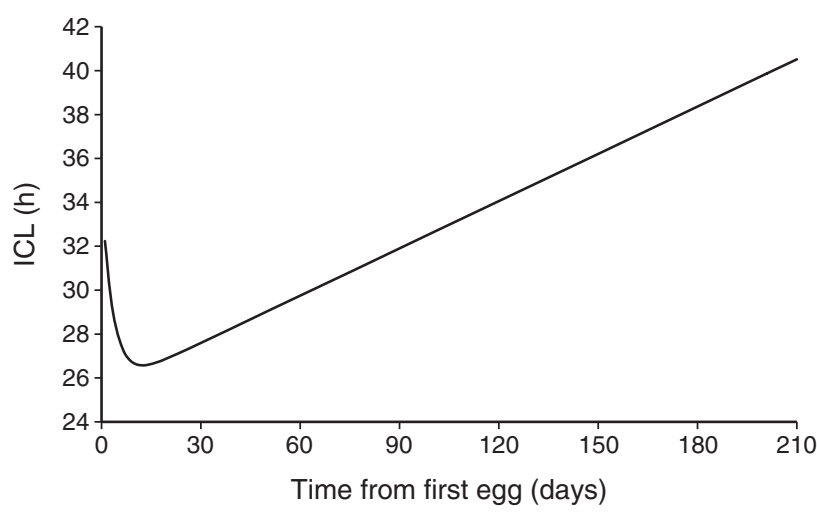

Fig. 2. The mean change in internal cycle length (ICL) over time for broiler breeders. to the average values were $5.3 \%$ for $a, 11.3 \%$ for $c, 4.5 \%$ for $d$, and $21.2 \%$ for $x$. Therefore, the equation obtained was

$$
\begin{gathered}
\mathrm{YW}=18.03 \times\left(1-\mathrm{e}^{-0.015 \times(t-103.4)}\right) \times \mathrm{e}^{(0.001 \times t)}, \\
R^{2}=0.94 .
\end{gathered}
$$

The average yolk weight predicted by the resulting equation and the yolk weights observed as a function of the age of the bird are illustrated in Fig. 3.

\section{Evaluation of the model for yolk weight}

The slope of the regression of residuals on predicted YW is $0.002(0.009)$. Considering the actual $R^{2}$ of 0.996 , the regression of residuals on observed values is $1-0.996=0.004$. The similarity of the slope and $1-R^{2}$ is evidence that the model is unbiased.

\section{Modelling albumen and shell data}

Linear regression analyses were performed using the natural $\operatorname{logs}(\ln )$ of albumen weight on yolk weight and $\ln$ (yolk + albumen) weight on $\mathrm{ln}$ shell weight, using individual eggweight data. The coefficients a and $\mathrm{b}$ estimated for AW were $14.38( \pm 0.388)$ and $0.375( \pm 0.009)$, and for SW they were $0.358( \pm 0.023)$ and $0.687( \pm 0.016)$, respectively. The standard errors for the estimated coefficients relative to the average values of a and $\mathrm{b}$ were 2.7 and $2.5 \%$ for $\mathrm{AW}$ and $6.5 \%$ and $2.3 \%$ for SW, respectively. The resulting equations for AW and SW are described as follows:

$$
\begin{gathered}
\mathrm{AW}=14.38 \times \mathrm{YW}^{0.375}, R^{2}=0.99, P<0.0001, \text { and } \\
\mathrm{SW}=0.358 \times \mathrm{CW}^{0.687}, R^{2}=0.99, P<0.0001 .
\end{gathered}
$$

In general, these equations present a good fit of the data observed, as can be seen in Fig. 4.

\section{Predicting egg weight from egg components}

The proportions of the predicted values for YW, AW and SW for 3100 eggs in the laying period from 23 to 60 weeks of age are shown in Fig. 5. As the age of broiler breeder hens

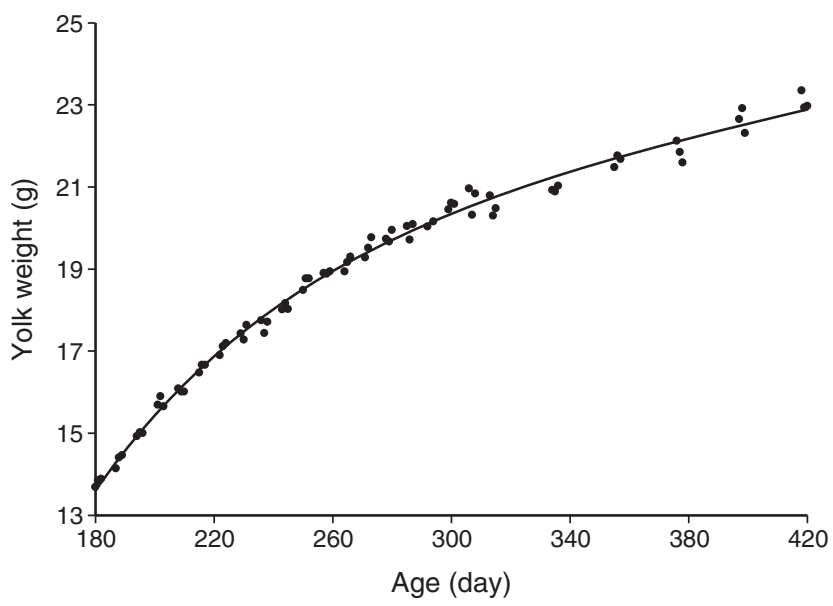

Fig. 3. The average yolk weight predicted by equation (-) and observed (๑) as a function of the age of the bird. 


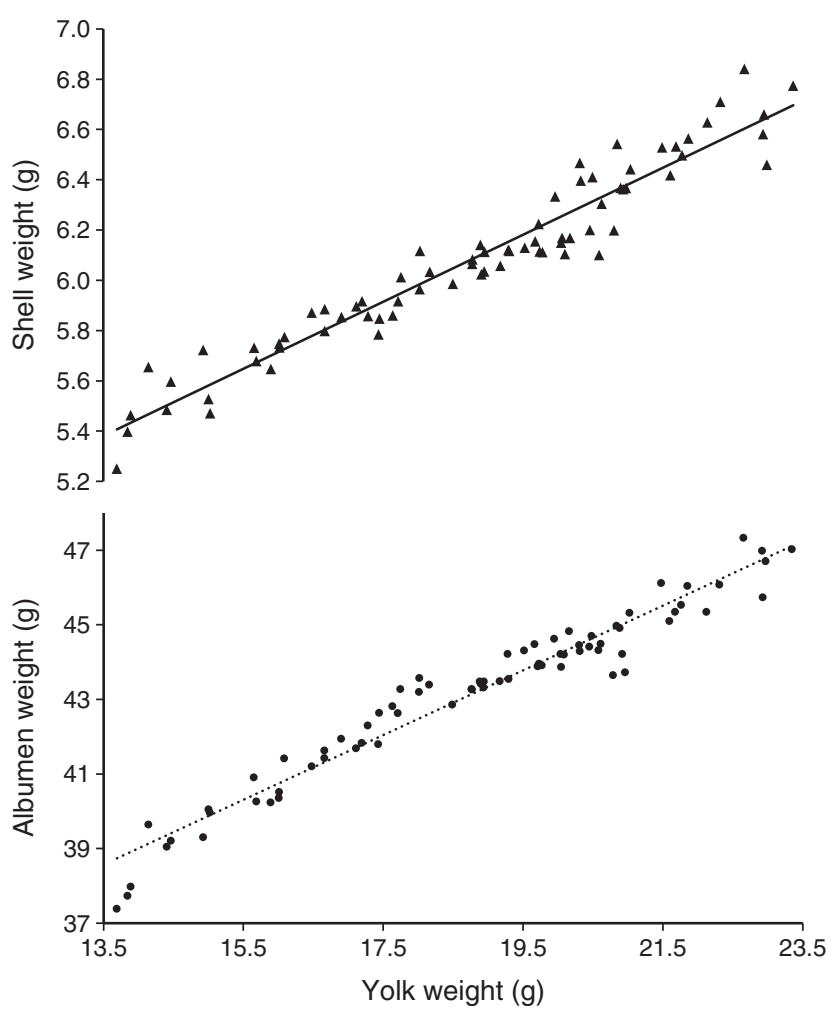

Fig. 4. The relationship between shell weight $(\mathbf{A})$ and albumen weight (๑) with yolk weight.

increased, the mean proportion of yolk increased, but the proportion of albumen and shell decreased. The model can be used to analyse the changes in the component proportions at a given age.

Equations 11, 12 and 13 were integrated into a model to predict egg weight, based on egg component weights over the entire laying period ( $\mathrm{YW}+\mathrm{AW}+\mathrm{SW})$. These values were plotted together with the mean egg weights observed (Fig. 6). However, it was not possible to obtain a good fit for egg weights at the start of egg production (up to $55 \mathrm{~g}$ or 180 days of age), with the predicted weights being overestimated in this period. This factor is associated with a high standard error in the predictions (4-6 g) up to this age, resulting in a variation of $10 \%$, but for egg weight $>55 \mathrm{~g}$, the error is minimised to $1-1.5 \mathrm{~g}(\sim 1 \%)$.

\section{Abnormal egg production}

\section{Double-yolked eggs}

The estimated values $\left( \pm\right.$ s.e.) of the parameters $\mathrm{DY}_{\max }$ and $k$ obtained in Eqn 7 were $2.275( \pm 0.363)$ and $0.209( \pm 0.036)$, respectively. The errors of the coefficients relative to the average values were $15.9 \%$ for $\mathrm{DY}_{\max }$ and $17.0 \%$ for $k$. The resultant equation was

$$
\mathrm{DY}=2.275 \times \mathrm{e}^{(0.209 \times \mathrm{TFE})}, R^{2}=0.80 .
$$

On the basis of individual observations of egg production, it was observed that the chance of a double-yolked egg being laid
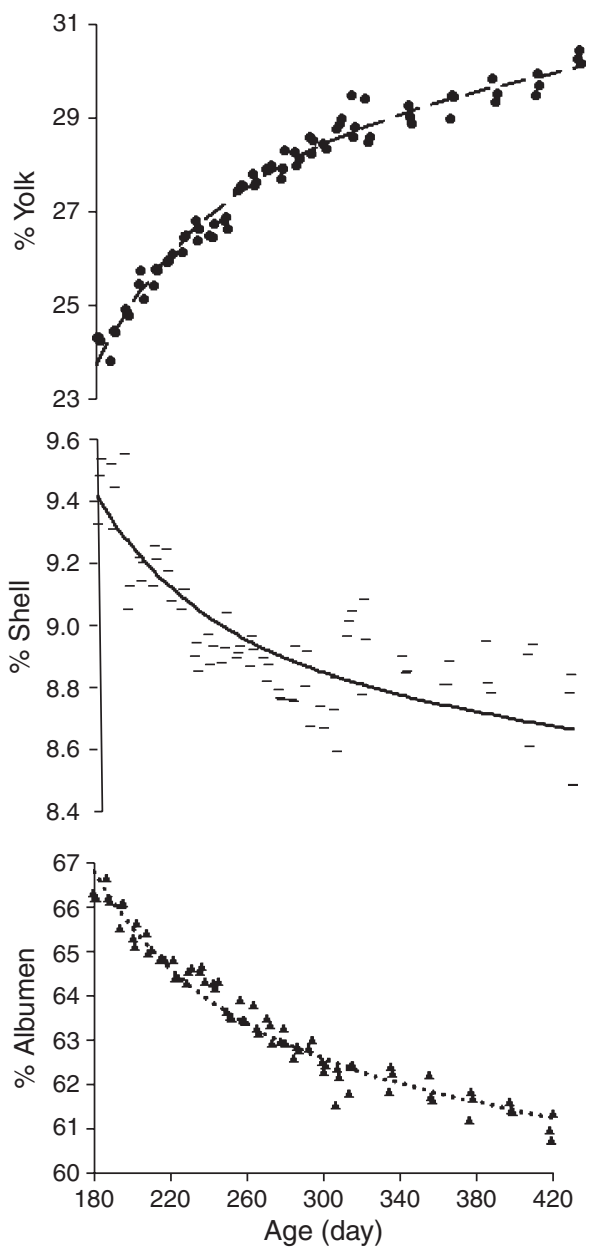

Fig. 5. Relationship between the observed proportions of yolk $(\bullet)$, shell (-) and albumen $(\mathbf{\Delta})$ in the egg and predicted $(---),(-)$ and $(\ldots)$, respectively with age. Data from 60 Cobb hens from 23 to 60 weeks of age.

by the flock was $\sim 0.59 \%$ ( 0.006 of all eggs laid $)$. The minimum proportion of double-yolked eggs relative to total eggs produced was observed in our study to be $0.047 \%$ after $8-9$ weeks, starting from the age at first egg. The curve illustrating the proportion of double-yolked eggs produced, starting from the age at first egg, is shown in Fig. 7.

\section{Soft-shelled eggs}

The estimated values ( \pm s.e.) for the parameters $a, b, R$, and $c$ were $1.126( \pm 0.158),-0.148( \pm 0.120), 0.024( \pm 0.001)$ and $-0.056( \pm 0.015)$, respectively. The errors of the coefficients relative to the average values were $14 \%$ for $a, 81 \%$ for $b, 4 \%$ for $R$ and $26.9 \%$ for $c$. The resultant equation was

$$
\begin{aligned}
\mathrm{SS}= & 1.126+0.148 /(1-0.024 \times \mathrm{TFE}) \\
& -0.056 \times \mathrm{TFE}, R^{2}=0.51 .
\end{aligned}
$$

The number of soft-shelled eggs was predicted by Eqn 15 and the proportion relative to the total number of eggs produced for broiler breeder hens of Cobb strain is shown in Fig. 7. 


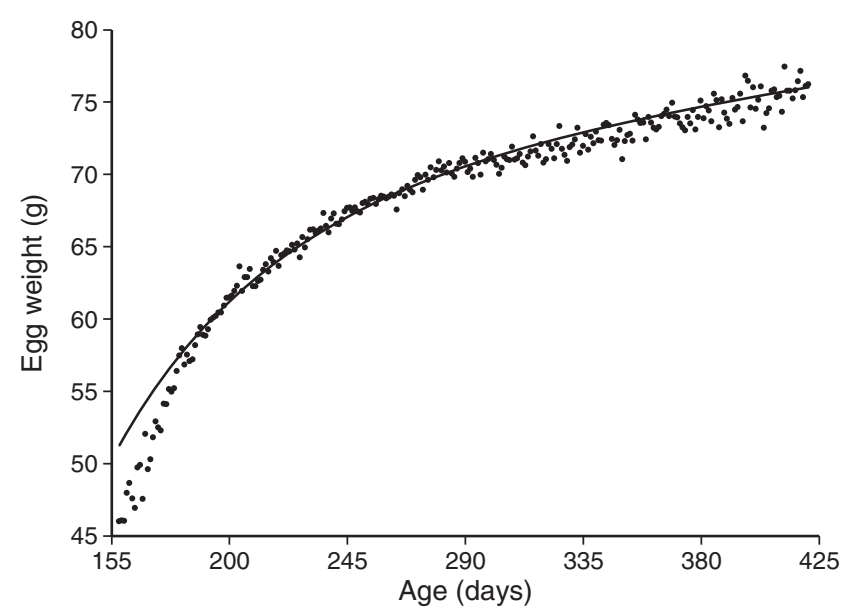

Fig. 6. The average egg weight predicted by equation (-), and the weight of eggs observed $(\bullet)$ as a function of age of bird.

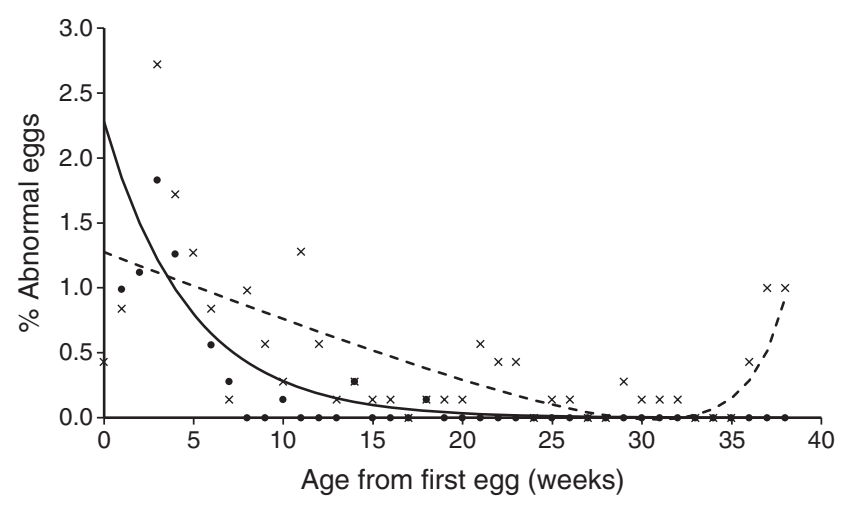

Fig. 7. Relationship between the observed occurrence of double-yolked $(\bullet)$ and soft-shelled eggs $(\times)$ and estimated $(-),(--)$, respectively, as a function of age of broiler breeder.

\section{Evaluation of the model for egg weight}

The residuals (er) calculated by the difference between observed and predicted egg weights were plotted against the predicted values of egg weight (Fig. 8) to evaluate the model obtained.

The slope $\left(b_{1}\right)$ of EW was $0.089( \pm 0.011)$, and the coefficient of determination $\left(R^{2}\right)$ was 0.975 , so the slope is $1-0.975=0.025$. This similarity between the slopes confirmed that the model is unbiased.

\section{Discussion}

Because of the lack of published information on the reproductive performance of broiler breeders, the aim of the present study was to collect more data on the changes that occur in internal cycle length, rate of egg production, egg component weights and the proportion of abnormal eggs laid by broiler breeders from 23 to 60 weeks of age. The prime sequence or longest sequence seen in the present study ( $\sim 20$ eggs) was equal to that reported by Robinson et al. (1992), but considerably greater than that reported by Nonis and Gous (2013), who reported that the longest sequence length observed in one of their studies was

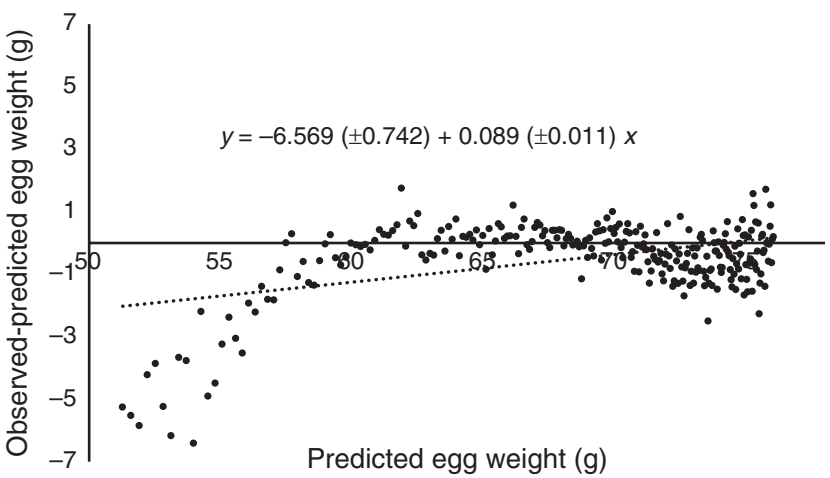

Fig. 8. Plot of observed minus predicted egg weight versus predicted egg weight.

only 10 eggs. The data shown in Fig. 1 are very different from those observed by Johnston and Gous (2007c) who analysed the egg sequence of laying hens and observed considerably longer sequences. Such differences were expected as broiler breeder hens have not been selected as intensely for reproductive capacity as have commercial laying hens, and consequently, their rates of lay are lower, and they exhibit more irregularity in egg laying, with shorter sequences and longer pauses. According to Robinson et al. (1993), egg production rates are positively correlated with the length of the prime sequence, i.e. hens with higher laying rates have longer sequences.

Under normal lighting conditions ( $16 \mathrm{~h}$ of light), the first egg of a sequence is laid early in the morning or about $9-10 \mathrm{~h}$ after the onset of darkness. Each subsequent oviposition occurs progressively later in the day, at intervals slightly longer than $24 \mathrm{~h}$, on successive days. During long sequences, oviposition time increases by a similar increment each day (Reynard and Savory 1999). The last egg of a sequence is normally laid during the afternoon (Gilbert and Wood-Gush 1971). Most ovulation sequences end with the absence of a mature follicle in the hierarchy on the day (Gilbert 1972). Several studies support this theory (Gilbert and Wood-Gush 1971; Reynard and Savory 1999; Johnston and Gous 2007c; Nonis and Gous 2013).

Hens that lay long sequences usually have very short follicular maturation rates (ICL), of $24 \mathrm{~h}$ or less, while hens that have slow rates of follicular maturation, of between 26 and $28 \mathrm{~h}$, lay short sequences of 2-3 days in duration (Etches and Schoch 1984). ICL expresses the lag between successive ovulations and is a measure of the synchronisation between follicle maturation and the circadian rhythm that controls LH release. ICL increases with age, due to the longer time needed to mature the follicles (Johnston and Gous 2003). Therefore, so as to reproduce this curvilinear effect, the ICL needs to be longer than $24 \mathrm{~h}$ initially, before decreasing with advancing time from first egg, in some cases to below the daylength, and subsequently increasing to $>24 \mathrm{~h}$ (Johnston and Gous 2006).

The values found in the present study for the parameters $a, b$, $R$ and $c$ are 25.44, 8.99, 0.748 and 0.072 , respectively, while the equivalent values reported by Gous and Nonis (2010) were $23.05,2.49,0.981$ and 0.022 . Because these parameters have no biological meaning, it is not possible to compare them other 
than by viewing the resultant graphs. It is, therefore, relatively difficult to find suitable values for the four parameters that produce a realistic mean sequence length for the genotype as well as a rate of lay comparable to the standard performance of the strain, and every experiment in which these parameters are measured will produce a different set of values for the four parameters. For this reason alone, the measurement of ovulation sequences in broiler breeders, as reported here, provides information invaluable to simulation modellers attempting to describe the potential performance of these hens. Because the fitted equation in the present study represented the mean ovulation rate of a population, the reproductive performance of the best producers, whose ICL dropped to $<24 \mathrm{~h}$ for a period of time, was masked by the poorest producers. In generating individual laying potentials in a stochastic model, the variances of and co-variances between parameters used are as important as the means of each parameter. More accurate estimates of these variances and co-variances can be made as the information on the reproductive performance of broiler breeders is increased.

According to Nonis and Gous (2013), it is preferable to calculate egg weight as the sum of the weights of its three components if the objective is to determine the amount of each essential nutrient required to produce an egg. This is because the relative proportions of the three components change over time; so, using a fixed composition would lead to errors when calculating the nutrients required per $g$ of egg output. Accounting for these changes is possible by predicting both the rate of production of ova and the average yolk weight over time, and then making use of the allometric relationships among the yolk, albumen and shell to calculate the weights of these components (Emmans and Fisher 1986).

Two approaches were used to predict yolk weight (YW) as a function of age, namely, the model proposed by Gous and Nonis (2010) and a compartmental model proposed by McMillan et al. (1970). The compartmental model was chosen because prediction bias appeared to be lower and the parameters generated have biological meaning.

The equation used to estimate the weight of the yolk over time fitted the data well (Fig. 3), with good prediction bias. An adequate estimation of yolk weight needs to be made because the values have a direct influence on estimates of shell and albumen weights used in the allometric calculations (Fig. 4). The present study confirmed the suitability of using allometric functions to predict the proportional changes in the egg components (Fig. 4), as proposed by Emmans and Fisher (1986), Johnston and Gous (2007c) and Gous and Nonis (2010).

The estimated allometric coefficients for predicting albumen and shell weight were close to those of Gous and Nonis (2010), who, working with Cobb and Ross broiler breeders, found values ranging from 9.58 to 14.73 and from 0.50 to 0.325 (for $a$ and $b$ in the albumen equation, respectively) and from 0.188 to 0.194 and from 0.832 to 0.848 (for $a$ and $b$ in the shell equation, respectively). In their study, Gous and Nonis (2010) found large differences between the two strains. Therefore, it seems essential to establish these parameters for each strain to improve the accuracy of model prediction between strains.

Figures 3-5 illustrate the accuracy of prediction of yolk weight from age and albumen and shell weights by using allometry. The equations used to predict yolk weight as a function of age, and the allometric functions that predicted albumen and shell weight from egg weight, all performed adequately, whereas the combination of these equations for predicting egg weight was less accurate during the initial few weeks of production (Fig. 7). During the first 40 days after sexual maturity, the predicted egg weight was higher than the measured weight. This is partially the result of the lower weight of albumen predicted during this period (Fig. 4). Nonis and Gous (2013) demonstrated that the amount of albumen secreted around the yolk during egg formation varies between individuals and from egg to egg; therefore, it is not unlikely that the proportions of the two components are inconsistent at a given age. Another reason for the error in estimating the initial egg weight is that only a small number of eggs were produced in the initial stages of lay and there was great variation between egg weights, with the birds exhibiting a rapid initial increase in the weight of the components of eggs. Equations that estimate egg weight directly as a function of age are thus likely to fit better than models that estimate each compartment separately through allometric functions, as proposed in the present work, but the added accuracy is of little value compared with the additional information obtained by estimating the weights of the components and adding these together to obtain the egg weight.

As hens become older and yolk and albumen weights increase, the shell becomes thinner because the increase in shell weight takes place at a decreasing rate relative to the egg contents (Johnston and Gous 2007a). These results present convincing evidence that the proportions of yolk, albumen and shell change as the hen ages (Fig. 5).

Yu et al. (1992) observed that 0.023 of all eggs laid by broiler breeders between 19 and 29 weeks of age were doubleyolked. Gous and Cherry (2004) observed that double-yolked eggs made up $2-4 \%$ of all eggs laid by birds during the period of 25-60 weeks of age, and Ciacciariello and Gous (2005) reported a rate of $\sim 0.04$ during the period of $23-56$ weeks of age. These rates of production of double-yolked eggs are considerably higher than observed in the trial reported here (0.006), indicating the wide differences in this characteristic among flocks.

It would appear that the fit of the data from Eqn 15 was unsatisfactory in predicting occurrence of soft-shelled eggs $\left(R^{2}=0.51\right)$. However, considering that the occurrence of soft-shelled eggs is not normal, this low $R^{2}$-value can be explained by the higher variation of these data due to different physiological states in specific situations. As with double-yolked eggs, the incidence of soft-shelled eggs is considerably greater in young broiler breeders, especially when photostimulation occurs early. The incidence is also higher in broiler breeders ( 0.011 of all eggs laid vs 0.003 in laying hens, as reported by Johnston and Gous 2007b). The likely cause of soft-shelled eggs in older birds is the less efficient absorption and utilisation of dietary calcium for shell formation (Hansen et al. 2003). These eggs cannot be used for hatching purposes, thus reducing the number of hatching eggs produced by the hens. A critical stage in the production of eggs for broiler breeders is from photostimulation to peak production. During this time, the number of yellow follicles is influenced by the age at 
photostimulation, feeding level and bodyweight (Renema et al. 1999). Broiler breeder hens that begin to lay before they are sufficiently mature somatically, or are overfed, may exhibit excessive follicular development, which will result in reproductive abnormalities that include the production of abnormal eggs (egg shells of poor quality and double-yolked eggs) and internal ovulations.

\section{Conclusions}

On the basis of the results obtained, the model developed here is an accurate reflection of the changes that occur in the number of eggs produced by broiler breeders as well as in the egg itself and in its components over the entire laying period. Using the estimates of the means and variances reported in this paper, of each of the parameters involved, this model can thus be used in predicting the nutrient requirements of individual broiler breeder hens, which, when combined with simulated data from a large number of individuals, will accurately describe the laying performance of a flock of broiler breeders. The challenge that remains is to predict the consequences of an inadequate nutrient intake on egg component weights and rate of lay.

\section{Acknowledgements}

The authors gratefully acknowledge the financial support of the Brazilian research financing institution FAPESP - Fundação de Amparo à Pesquisa do Estado de São Paulo.

\section{References}

Ahn DU, Kim SM, Shu H (1997) Effect of egg size and strain and age of hens on the solids content of chicken eggs. Poultry Science 76, 914-919. doi:10.1093/ps/76.6.914

Anderson GB, Bolton W, Jones RM, Draper MH (1978) Effect of age of the laying hen on the composition of the egg. British Poultry Science 19, 741-745. doi:10.1080/00071667808416538

Christmas RB, Harms RH (1982) Incidence of double yolked eggs in the initial stages of lay as affected by strain and season of the year. Poultry Science 61, 1290-1292. doi:10.3382/ps.0611290

Ciacciariello M, Gous RM (2005) To what extent can the age at sexual maturity of broiler breeders be reduced? South African Journal of Animal Science 35, 73-82.

Cobb (2012) Breeder management supplement. Cobb Vantress. Siloam Springs, AR.

Emmans GC, Fisher C (1986) Problems in nutritional theory. In 'Nutrient requirements of poultry and nutritional research'. (Eds C Fisher, KN Boorman) pp. 9-40. (Butterworths: London)

Etches RJ, Schoch JP (1984) A mathematical representation of the ovulatory cycle of the domestic hen. British Poultry Science 25, 65-76. doi:10.1080/ 13632758408454843

Gilbert AB (1972) The activity of the ovary in relation to egg production. In 'Egg formation and production'. (Eds BM Freeman, PE Lake) pp. 3-17. (British Poultry Science Ltd: Edinburgh, UK)

Gilbert AB, Wood-Gush DGM (1971) Ovulatory and ovipository cycles. In 'Physiology and biochemistry of the domestic fowl. Vol. 3'. (Eds D Bell, BM Freeman) pp. 1353-1378. (Academic Press: London)

Gous RM, Cherry P (2004) Effects of body weight at, and lighting regimen and growth curve to, 20 weeks on laying performance in broiler breeders. British Poultry Science 45, 445-452. doi:10.1080/00071660400001256

Gous RM, Nonis MK (2010) Modelling egg production and nutrient responses in broiler breeder hens. The Journal of Agricultural Science 148, 1-15. doi:10.1017/S0021859610000183
Hansen KK, Kittok RJ, Sarath G, Toombs CF, Caceres N, Beck MM (2003) Estrogen receptor- $\alpha$ population change with age in commercial laying hens. Poultry Science 82, 1624-1629. doi:10.1093/ps/82.10.1624

Harms RH, Hussein SM (1993) Variation in yolk: albumen ratio in hen eggs from commercial flocks. Journal of Applied Poultry Research 2, 166-170. doi:10.1093/japr/2.2.166

Hussein SM, Harms RH, Janky DM (1993) Effect on the yolk to albumen ratio in chicken eggs. Poultry Science 72, 594-597. doi:10.3382/ps.072 0594

Johnston SA (2004) A stochastic model to predict annual egg production of a flock of laying hens. PhD. Agric. Thesis, University of KwaZulu-Natal, South Africa.

Johnston SA, Gous RM (2003) An improved mathematical model of the ovulatory cycle of the laying hen. British Poultry Science 44, 752-760. doi:10.1080/00071660310001643723

Johnston SA, Gous RM (2006) Modelling egg production in laying hens. In 'Mechanistic modelling in pig and poultry production'. (Eds RM Gous, TR Morris, C Fisher) pp. 188-208. (CAB International: Wallingford, UK)

Johnston SA, Gous RM (2007a) Modelling the changes in the proportions of the egg components during a laying cycle. British Poultry Science 48, 347-353. doi:10.1080/00071660701381134

Johnston SA, Gous RM (2007b) Extent of variation within a laying flock: attainment of sexual maturity. double-yolked and soft-shelled eggs. Sequence lengths and consistency of lay. British Poultry Science 48, 609-616. doi:10.1080/00071660701573037

Johnston SA, Gous RM (2007c) A mechanistic stochastic population model of egg production. British Poultry Science 48, 224-232. doi:10.1080/ 00071660701227493

McMillan I, Fitz-Earle M, Butler L, Robson DS (1970) Quantitative genetics of fertility I. Lifetime egg production of Drosophila melanogaster theoretical. Genetics 65, 349-353.

Nonis MK, Gous RM (2013) Modelling changes in the components of eggs from broiler breeders over time British Poultry Science 54, 603-610. doi:10.1080/00071668.2013.830173

Reidy TR, Atkinson JL, Leeson S (1994) Strain comparison of turkey egg components. Poultry Science 73, 388-395. doi:10.3382/ps.0730388

Renema RA, Robinson FE, Newcombe M, McKay RI (1999) Effect of body weight and feed allocation during sexual maturation in broiler breeder hens. 1. Growth and carcass characteristics. Poultry Science 78, 619-628. doi:10.1093/ps/78.5.619

Reynard M, Savory CJ (1999) Stress-induced oviposition delays in laying hens: duration and consequences for eggshell quality. British Poultry Science 40, 585-591. doi:10.1080/00071669986945

Robinson NA, Robinson FE, Hardin RT, Tchir B (1992) Reproductive senescence in egg-type chickens: effects on egg production, sequence length and inter-sequence pause length. Poultry Science 71, 128. [Abstract]

Robinson FE, Wilson JL, Yu MW, Fasenko GM, Hardin RT (1993) The relationship between body weight and reproductive efficiency in meattype chickens. Poultry Science 72, 912-922. doi:10.3382/ps.0720912

Rossi M, Pompei C (1995) Changes in some egg components and analytical values due to hen age. Poultry Science 74, 152-160. doi:10.3382/ ps. 0740152

SAS Institute (2002) 'SAS user's guide: statistics.' (SAS Institute Inc.: Cary, NC)

St-Pierre NR (2003) Reassessment of biases in predicted nitrogen flows to the duodenum by NRC 2001. Journal of Dairy Science 86, 344-350. doi:10.3168/jds.S0022-0302(03)73612-1

Yu MW, Robinson FE, Charles RG, Weingerdt R (1992) Effect of feed allowance during rearing and breeding on female broiler breeders. 2 . Ovarian morphology and production. Poultry Science 71, 1750-1761. doi: $10.3382 / \mathrm{ps} .0711750$

Zuidhof MJ, Bignell D, Robinson FE (1999) Egg production and sequence analyser. Version 3.00. Alberta Poultry Research Centre, Edmonton, Alberta, Canada. 